\title{
The effect of delayed weaning on the development of oral tolerance to soya-bean protein in pigs
}

\author{
BY B. G. MILLER ${ }^{1}$, C. T. WHITTEMORE 2 C. R. STOKES ${ }^{1}$ AND E. TELEMO \\ ${ }^{1}$ School of Veterinary Science, Bristol University, Langford House, Langford, Bristol BSI8 $7 D U$ \\ ${ }^{2}$ The Edinburgh School of Agriculture, West Mains Road, Edinburgh EH9 3JG \\ ${ }^{3}$ Department of Clinical Immunology, University of Gothenburg, Sweden
}

(Received 18 January 1993 -Revised 22 June 1993 - Accepted 28 July 1993)

\begin{abstract}
The antibody response to a dietary antigen (soya-bean protein) and the development of oral tolerance was studied in pigs in a family pen system where the piglets are left with their mothers and gradually wean themselves onto a soya-bean-based diet over a 12 week period. In the first experiment three groups of pigs (eight pigs/group) aged either 2,8 or 13 weeks were immunized with soya-bean protein or ovalbumin (OvA; controls) intra-peritoneally (i.p.) in Quill A adjuvant and subsequently boosted 2 weeks later. All groups showed an IgG response to the injected antigens indicating lack of tolerance induction to the dietary antigen. Interestingly the groups injected with OvA showed an almost identical response to soyabean protein as the groups injected with soya-bean protein. In a second experiment with a similar protocol, soya bean was withdrawn from the feed before immunization which resulted in lack of response to soya-bean protein in the groups injected with OvA and a lack of response to injected soya-bean protein in the 14-week-old group, indicating that systemic tolerance was established by 12 weeks of age. The results from the two experiments suggest a compartmentalized response to soya-bean protein i.e. local antibody production to dietary soya bean along with systemic tolerance to injected soya-bean protein. The work also suggests that delayed 'natural' weaning may avoid damaging hypersensitivity reactions associated with early weaning.
\end{abstract}

Weaning: Immunological tolerance: Soya bean: Pigs

Early weaning is often accompanied by gastrointestinal upset, elevated susceptibility to infection, and a higher risk of hypersensitivity reactions to food constituents in both humans and domestic animals. The average weaning age for commercial pigs in the UK is between 3 and 4 weeks, the aim being to remate the sow as soon as possible after parturition and maximize output of pigs/sow per year. Early weaning for the pig, however, may induce a potentially severe digestive upset and growth check and predispose to Escherichia coli enteritis which if untreated may be fatal (Miller et al. 1984). In contrast, pigs weaned later, e.g. $>10$ weeks, rarely develop clinical problems when removed from the sow.

We have suggested (Miller et al. 1984) that a transient hypersensitivity reaction to ingredients in the weaner diet may be a contributory factor to postweaning enteritis and that pigs weaned at 3 weeks onto a soya-bean-based diet show an initial hypersensitivity response, i.e. develop serum anti-soya-bean immunoglobulin $G$ (IgG) before the development of systemic tolerance (Bailey et al. 1993). A similar mechanism has also been shown in other species (Stokes \& Swarbrick, 1977; Telemo et al. 1987; Wold et al. 1988). Recently we have shown that during the sucking period the piglets are exposed to dietary antigens in colostrum and milk which, along with specific antibodies, can modify the immune response of the piglets to these antigens (Telemo et al. 1991).

The aim of the work reported here was to investigate whether pigs can develop oral 
tolerance to soya-bean protein contained in the sow's diet and their own grower diet if weaning is delayed. This more gradual dietary change may minimize damaging hypersensitivity reactions during the transition phase. The sucking period also provides a 'privileged' environment for the intestinal immune system, since the animals obtain a degree of enteric protection from the IgA, lactoferrin and lactoperoxidase $(E C 1.11 .1 .7)$ found in their mother's milk (Holmgren et al. 1981; Newby et al. 1982).

\section{MATERIALS AND METHODS}

Pigs were from the Edinburgh School of Agriculture Family Pen system. Animals reared in the family pen are left with their mothers until they are sent for slaughter at pork weight $(60-80 \mathrm{~kg})$. The boar is re-introduced to the family group of four sows at $15-21 \mathrm{~d}$ postpartum to stimulate lactational oestrus and achieve successful service. This system was initially developed to improve psychological aspects of animal welfare (Stolba \& Wood-Gush, 1984). It is, however, particularly suited to the questions posed in this paper since the offspring are not weaned abruptly but instead gradually wean themselves by the time they are 12 weeks of age. The pigs used were Large White $\times$ Landrace.

\section{Diet}

The diets used are described in Table 1. Only the soya-bean diets were fed in Expt 1 whereas both the soya-bean and the soya-bean-free diets were fed in Expt 2, the soya-bean-free diets being introduced to the sow and her progeny a minimum of 2 weeks before the first immunization. In the soya-bean-free diet the proportions of fish meal and cereals were raised to achieve comparable protein levels $(170 \mathrm{~g} / \mathrm{kg})$ in the two diets. Sows were fed twice daily and the piglets had ad lib. access to the grower diets from 2 weeks of age.

\section{Antigens}

The soya-bean antigen both for immunization and antibody determination was prepared by stirring a defatted soya-bean flour (Protisoya; Spillers Premier Products, Ware, Herts.) in Tris- $\mathrm{HCl}$ buffer containing $10 \mathrm{~mm}$-2-mercaptoethanol for $1 \mathrm{~h}$ at $\mathrm{pH} \mathrm{7.8.} \mathrm{After}$ centrifugation at $10000 \mathrm{~g}$ the supernatant was reduced to $\mathrm{pH} 4.8$ to precipitate the soyabean proteins. The precipitate was redissolved in phosphate-buffered saline (PBS), freezedried and stored desiccated at $4^{\circ}$. The chicken egg ovalbumin (OvA) used was grade $\mathrm{V}$ supplied by Sigma (A5503; Poole, Dorset). The saponin Quill A (Superfos Biosector, Vedbaek, Denmark) was used as adjuvant.

Pigs were immunized intraperitoneally (i.p.) with $100 \mathrm{mg}$ Quill A+200 $\mathrm{mg}$ (soya-bean antigen or OvA) $/ \mathrm{kg}$ body weight ${ }^{0.75}$, in an attempt to scale the antigenic challenge to the widely differing sizes between experimental groups.

\section{Experimental design}

Expt 1. The experimental protocol for both Expt 1 and 2 is shown in Table 2. Groups of eight pigs were immunized by i.p. injection of either OvA $(\mathrm{O})$ or soya-bean antigen $(\mathrm{S})$ in Quill $\mathrm{A}$ adjuvant at 2,8 or 13 weeks of age, to create six experimental treatments: $2 \mathrm{wO}$; $2 \mathrm{wS} ; 8 \mathrm{wO} ; 8 \mathrm{wS}, 13 \mathrm{wO}$ and $13 \mathrm{wS}$. All pigs were subsequently boosted 2 weeks later with the same antigen. Blood samples were taken by vacutainer from the anterior vena cava of all pigs immediately before the first and second immunizations and finally 2 weeks later. The pigs injected with soya-bean antigen acted as controls for the anti-OvA response and the pigs injected with OvA acted as controls for the response to soya-bean antigen. Throughout Expt 1 the sows were given a diet containing soya bean, and soya bean was also present in the piglet grower diet which was available from 2 weeks of age. 
Table 1. Composition $(\mathrm{g} / \mathrm{kg})$ of soya-bean-based and soya-bean-free pig diets

\begin{tabular}{|c|c|c|c|c|}
\hline & \multicolumn{2}{|c|}{ Sow diet } & \multicolumn{2}{|c|}{ Grower diet } \\
\hline & + Soya & -Soya & + Soya & - Soya \\
\hline Barley & 580 & 775 & 172 & - \\
\hline Wheat & - & - & 150 & - \\
\hline Micronized wheat & - & - & - & 775 \\
\hline Flaked maize & - & - & 150 & - \\
\hline Wheatfeed & 88 & - & - & - \\
\hline Cooked oats & - & - & 150 & - \\
\hline Soya-bean meal & - & - & 80 & - \\
\hline Full fat soya bean & - & - & 100 & - \\
\hline Milk replacer & - & - & 50 & - \\
\hline Soya bean $44 \%$ & 120 & 一 & - & - \\
\hline Fishmeal blend & 30 & 120 & 125 & 200 \\
\hline Dry fat 50 & 50 & 30 & - & - \\
\hline Maize oil & - & - & $\cdots$ & 10 \\
\hline Sow vitamin \& mineral supplement & 25 & 25 & - & - \\
\hline Piglet vitamin \& mineral supplement & - & - & 5 & 5 \\
\hline Molasses & 50 & 50 & - & - \\
\hline Dark grains & 52 & - & - & - \\
\hline Dicalcium phosphate & 5 & - & 14 & 8 \\
\hline Salt & - & -- & 1 & 1 \\
\hline Vitamin E supplement & - & - & 3 & 1 \\
\hline \multicolumn{5}{|l|}{ Calculated to provide } \\
\hline $\mathrm{DE}(\mathrm{MJ} / \mathrm{kg})$ & $13 \cdot 2$ & $13 \cdot 2$ & $15 \cdot 2$ & $14 \cdot 6$ \\
\hline $\mathrm{CP}(\mathrm{g} / \mathrm{kg})$ & 173 & 170 & 235 & 222 \\
\hline Oil $(\%$ feed $)$ & $4 \cdot 3$ & $3 \cdot 3$ & $5 \cdot 7$ & 3.5 \\
\hline Lysine $(\mathrm{g} / \mathrm{kg})$ & $8 \cdot 1$ & $8 \cdot 6$ & 15 & 14 \\
\hline
\end{tabular}

$\mathrm{DE}$, digestible energy; $\mathrm{CP}$, crude protein $(\mathrm{N} \times 6.25)$.

Table 2. Age of pigs (weeks) at blood sampling and immunization in Experiments 1 and 2*

\begin{tabular}{|c|c|c|c|}
\hline $\begin{array}{l}\text { Treatment } \\
\text { group }\end{array}$ & $\begin{array}{l}\text { 1st blood sample and } \\
\text { primary injection }\end{array}$ & $\begin{array}{l}\text { 2nd blood sample and } \\
\text { secondary injection }\end{array}$ & Final blood sample \\
\hline \multicolumn{4}{|l|}{ Expt 1} \\
\hline $2 \mathrm{wO}$ & 2 & 4 & 6 \\
\hline $2 w S$ & 2 & 4 & 6 \\
\hline $8 w O$ & 8 & 10 & 12 \\
\hline $8 w S$ & 8 & 10 & 12 \\
\hline $13 w O$ & 13 & 15 & 17 \\
\hline $13 w S$ & 13 & 15 & 17 \\
\hline \multicolumn{4}{|l|}{ Expt 2} \\
\hline $11 \mathrm{wO}$ & 11 & 13 & 15 \\
\hline $1 \mathrm{IwS}$ & I I & 13 & 15 \\
\hline $14 \mathrm{wO}$ & 14 & 16 & 18 \\
\hline $14 \mathrm{wS}$ & 14 & 16 & 18 \\
\hline
\end{tabular}

$\mathrm{w}$, weeks of age; $\mathrm{O}$, immunized by intra-peritoneal injection with ovalbumin; $\mathrm{S}$, immunized by intra-peritoneal injection with soya-bean antigen.

* For details of experiments, see pp. 616618 . 


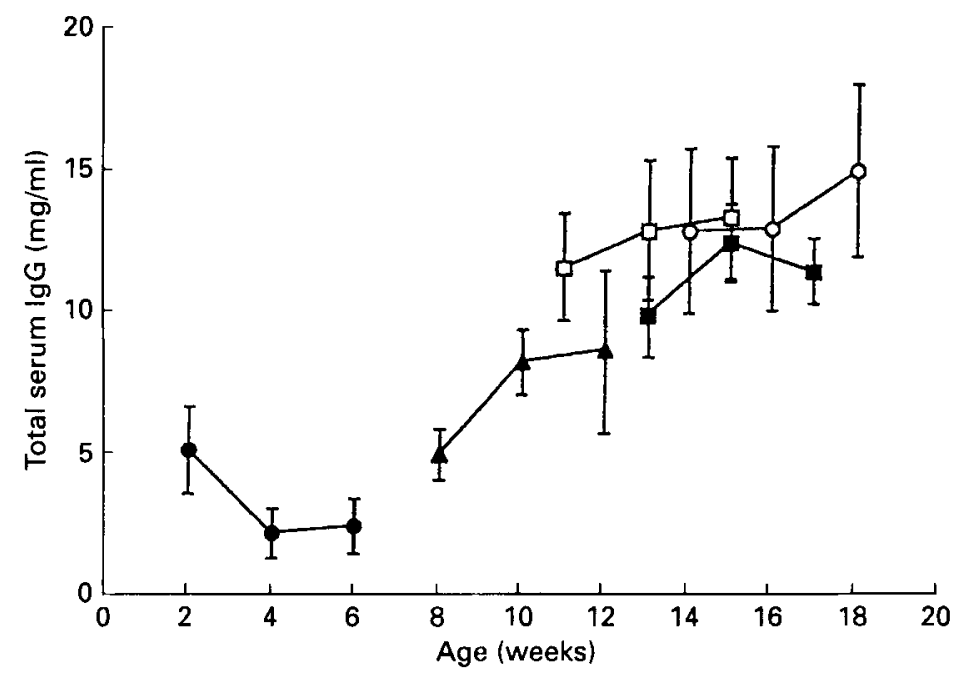

Fig. 1. The effect of age (weeks; w) on total concentration of IgG in serum of piglets immunized with ovalbumin (O) or soya-bean antigen (S). Symbols indicate different treatment groups: 2 wO\&S, $\triangle$ 8wO\&S, $\square$ 13wO\&S, $\square 11$ wO\&S, $O$ 14wO\&S. Values are means and standard deviations for sixteen piglets.

Expt 2. Groups of eight pigs were immunized when they were either 11 or 14 weeks of age with either soya-bean antigen or OvA, thus making four experimental treatments: $11 \mathrm{wS}, 11 \mathrm{wO}, 14 \mathrm{wS}$ and $14 \mathrm{wO}$. They were also boosted after 2 weeks and blood samples were taken immediately before the first and second immunizations and 2 weeks later. However, in contrast to Expt 1, both the sows' diet and the piglets' grower diet were made soya-bean-free before the first immunization ( 3 weeks for those immunized at 11 weeks and 2 weeks for those immunized at 14 weeks). This was done to ensure that when immunized i.p. with either the soya-bean antigen or the OvA in Quill A the response would not be complicated by a simultaneous response to dietary soya-bean.

\section{Serum antibody determination}

Blood samples were allowed to clot at room temperature, centrifuged and then serum was taken and stored at $-20^{\circ}$ for subsequent analysis. Total IgG was determined by radial immunodiffusion (Fahey \& McKelvey, 1965) using sheep anti-pig IgG, a reference pig serum previously calibrated for IgG being added to each plate.

Anti-soya-bean and anti-OvA IgG were determined by ELISA. Duplicate microtitre plates (Dynatech Laboratories Inc., VA, USA) were coated overnight with either soya-bean antigen or OvA $(10 \mathrm{mg} / \mathrm{ml})$ in carbonate-bicarbonate buffer, $\mathrm{pH} 9 \cdot 6$. Test samples were serially diluted $(\times 3)$ on both the OvA and soya-bean antigen-coated plates, in PBS containing $1 \mathrm{ml}$ Tween $20 / 1$ and incubated overnight at room temperature. Hyperimmune pig serum standards previously prepared against both soya-bean antigen and OvA by immunization were used as reference standards, being arbitrarily defined to contain 100000 ELISA units. Relevant standards were serially diluted $(\times 2)$ on each plate. Bound antisoya-bean or anti-OvA IgG was detected using sheep anti-pig IgG, followed by pig antisheep IgG conjugated to alkaline phosphatase $(E C 3.1 .3 .1$; both anti sera produced in our laboratory). The reaction was developed using the substrate $p$-nitrophenyl phosphate disodium (Sigma; $1 \mathrm{mg} / \mathrm{ml}$ in carbonate-bicarbonate buffer) and the absorbance read at 405 and $492 \mathrm{~nm}$ on a Titertek Multiscan (Flow Laboratories, Irvine, Rickmansworth, Herts.). Between each step the plates were washed with PBS-Tween. 

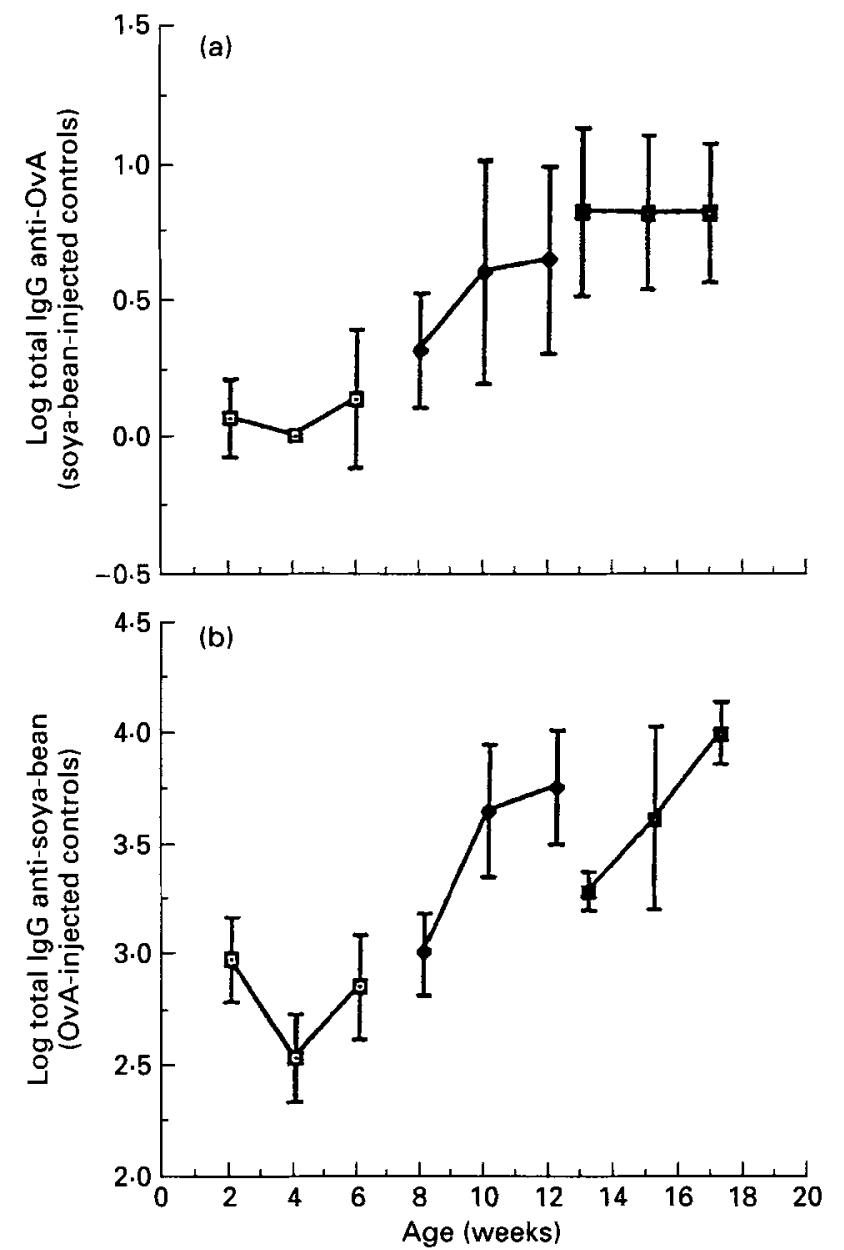

Fig. 2. The effect of age (weeks; w) on antigen-specific background (log ELISA units/ml) in serum of control piglets. (a) Anti-ovalbumin IgG in piglets injected with soya-bean antigen (S); (b) anti-soya-bean IgG in piglets injected with ovalbumin $(O)$. Symbols indicate different treatment groups: $\square 2$ wO\&S, $\bullet$ wO\&S, $\square 13$ wO\&S. Values are means and standard deviations for eight piglets.

Antibody levels were determined using an interactive computer program (ELISANALYSIS; J. H. Peterman, Birmingham, AL 35219, USA) and the results are expressed as ELISA units/mg total serum IgG. Antigen specificity was determined either with noncoated/coated plates or by blocking with the appropriate antigen. Undetectable levels were given an arbitrary value of 1 ELISA unit/ $\mathrm{ml}$ to allow subsequent mathematical analysis.

\section{RESULTS}

Total serum IgG levels $(\mathrm{mg} / \mathrm{ml})$ were markedly affected by age of the pig; in contrast, neither immunization nor the antigen used had an effect upon total serum IgG levels. Therefore, the mean values of total serum IgG for the five age groups of pigs are shown in Fig. 1. Total serum IgG concentration fell between 2 and 4 weeks of age, presumably reflecting the loss of maternally derived colostral antibody, but rose thereafter from 6 weeks to the end of the experiment.

In both experiments there was a parallel rise with age in both IgG anti-soya-bean and 


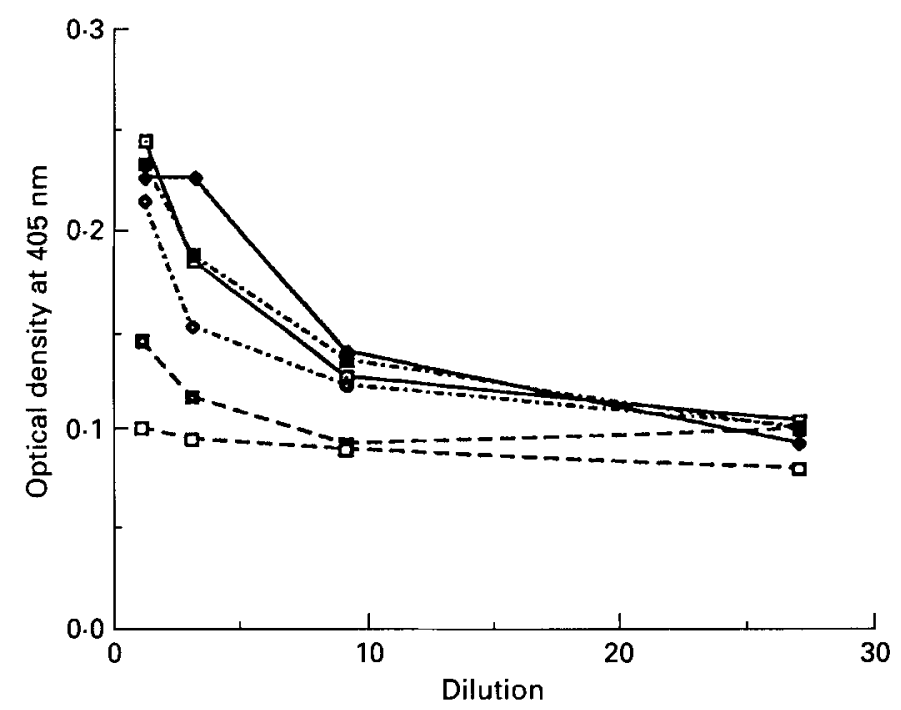

Fig. 3. Blocking of background IgG anti-ovalbumin (OvA) activity in two representative samples of serum ( 32 and 78 ) by the appropriate antigen OvA or by an unrelated antigen, human serum albumin (HSA). $\square$ sample 32 alone, - sample 78 alone, - sample 32 + Ova, sample 32 + HSA, $\square$ sample $78+$ HSA, $\square$ sample $78+$ OvA.

anti-OvA in control animals, i.e. those injected with the alternative antigen (Fig. 2). There was also a similar age-related increase in the preinjection values observed between groups. These values were shown to be antigen specific since they could be blocked by preincubation with the appropriate antigen but not by the unrelated antigen, human serum albumin (HSA), and uncoated ELISA plates were negative. Fig. 3 shows the effect of blocking with either HSA or OvA on samples 32 and 78, the two highest anti-OvA background values observed. This antigen-specific background is presumably a result of cross-reactivity. Thus if there is an increase in total IgG, whether due to clonal expansion of existing B cells or the generation of different clones, it will result in increased (albeit low) cross-reactivity. Thus these results, if expressed as total ELISA units $/ \mathrm{ml}$ of serum, show an increase with age in antigen specific antibody levels, even against OvA in control pigs (i.e. those injected with soya-bean antigen) which have neither been fed nor injected with OvA. Such a result would seem unlikely. However, when expressed as specific activity (ELISA units/mg total serum IgG) the anti-OvA background unstimulated levels (2wS, 8 wS and $13 w S$ ) do not change with age (Fig. 4). A similar result is obtained when anti-soya values (Fig. 5) are expressed as specific activity, in that the preinjection values for each group $(2 \mathrm{wO}, 8 \mathrm{wO}$ and $13 \mathrm{wO}$ ) do not increase with age. Therefore, results throughout this paper (other than Fig. 2) are expressed as a specific activity.

\section{Expt 1}

The pigs from all three age groups showed a similar pre-immunization IgG anti-soya-bean titre (Fig. 5). After challenge with soya-bean antigen in Quill A all groups responded both to the primary and secondary injections. Interestingly, the pigs injected with OvA in Quill $\mathrm{A}$ in the $8 \mathrm{wO}$ and $13 \mathrm{wO}$ groups showed an almost identical response to soya-bean antigen as the groups injected with soya-bean antigen whilst the $2 \mathrm{wO}$ group injected with OvA showed only a mild response to soya bean. It should be noted that the piglets had access to food containing soya bean, which they started eating at about 3 weeks of age. These results indicate a lack of tolerance to both dietary and injected soya bean. 


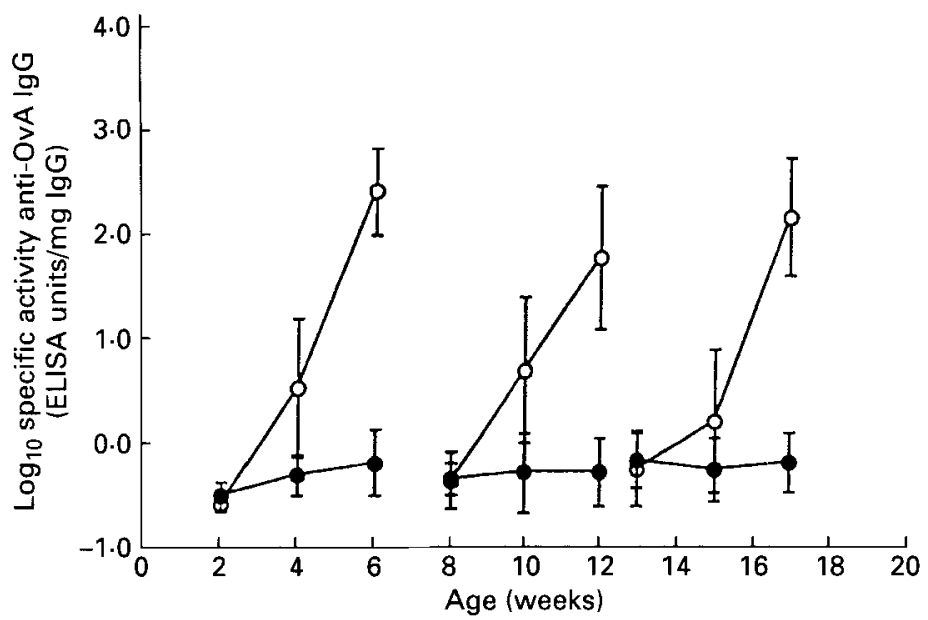

Fig. 4. Expt 1. IgG anti-ovalbumin (OvA) levels expressed as specific activity ( $\log _{10}$ ELISA units/mg total IgG) in piglets first injected with soya-bean antigen $(O)$ or ovalbumin $(\bigcirc)$ at 2,8 or 13 weeks of age. Values are means and standard deviations for eight piglets.

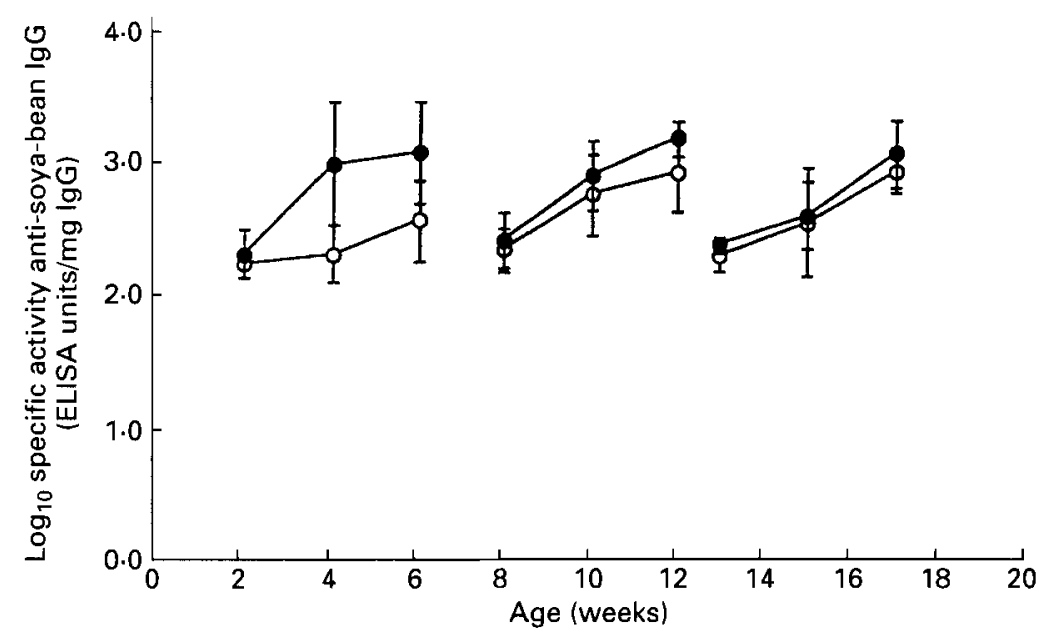

Fig. 5. Expt 1. IgG anti-soya bean levels expressed as specific activity ( $\log _{10}$ ELISA units/mg total lgG) in piglets first injected with soya-bean antigen (O) or ovalbumin $(O)$ at 2,8 or 13 weeks of age. Values are means and standard deviations for eight piglets. N.B. All piglets had access to a diet containing soya bean from 2 weeks of age.

None of the groups showed significant pre-immunization titres against OvA and all groups showed a similar IgG response to OvA upon challenge (Fig. 4). The challenge with soya-bean antigen in Quill A did not produce any anti-OvA response.

\section{Expt 2}

Fig. 6 shows that the $11 \mathrm{wS}$ group that was soya-bean-free from 8 weeks of age showed an IgG response to an injection of soya-bean antigen in Quill A whereas the 14wS group that was soya-bean-free from 12 weeks of age did not respond to the soya-bean antigen in Quill $A$, indicating that these latter pigs were systemically tolerant. In contrast to Expt 1 , no antisoya bean response was seen in the OvA-challenged pigs ( $11 \mathrm{wO}$ and $14 \mathrm{wO}$ ), although both 


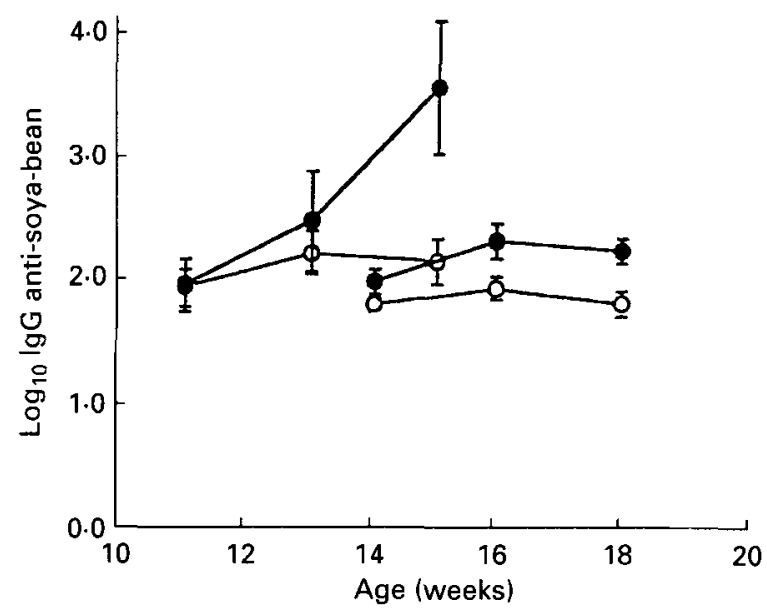

Fig. 6. Expt 2. IgG anti-soya bean levels expressed as specific activity ( $\log _{10}$ ELISA units/mg total IgG) in piglets first injected with soya-bean antigen $(\mathcal{O})$ or ovalbumin $(O)$ at 11 or 14 weeks of age. Values are means and standard deviations for eight piglets. N.B. The 11 -week group was soya-bean-free from 8 weeks of age, and the 14-week group was soya-bean-free from 12 weeks of age.

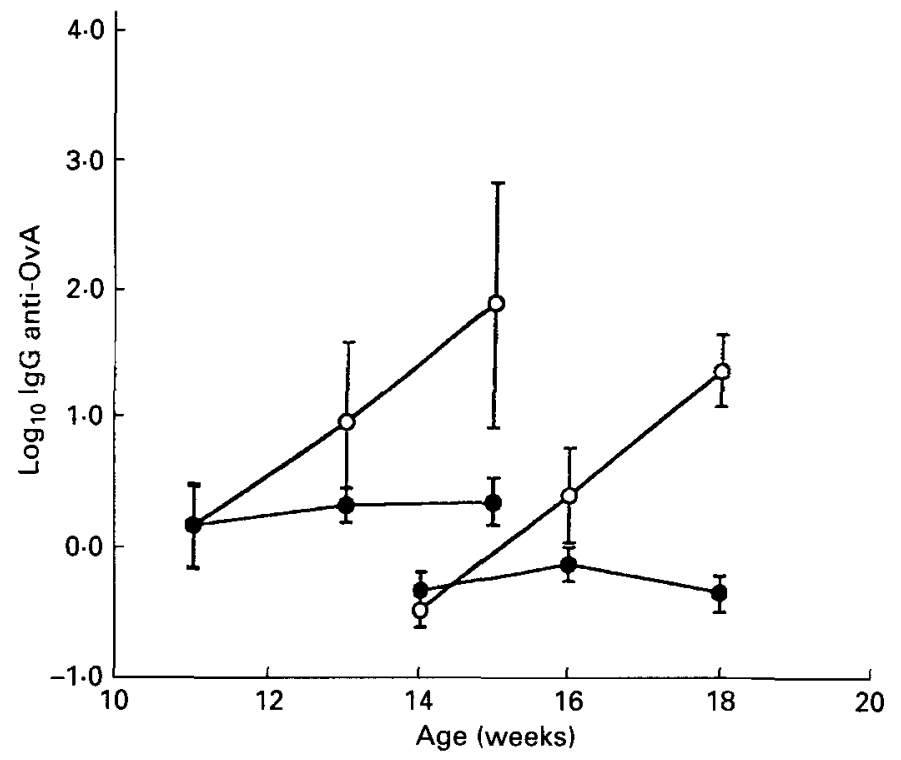

Fig. 7. Expt 2. IgG anti-ovalbumin (OvA) levels expressed as specific activity $\left(\log _{10}\right.$ ELISA units/mg total IgG) in piglets first injected with soya-bean antigen (O) or OvA (O) at 11 or 14 weeks of age. Values are means and standard deviations for eight piglets. N.B. The 11 -week group was soya-bean-free from 8 weeks of age and the 14-week group was soya-bean-free from 12 weeks of age.

groups showed a similar response to OvA (Fig. 6). As in Expt 1 pigs immunized against soya bean (1lwS and 14wS) failed to show an anti-OvA response (Fig. 7).

\section{DISCUSSION}

Following immunization with OvA in both Expt 1 and 2, in all five age groups there was an increase in anti-OvA IgG (Fig. 5 and 7 ) which responded to further immunization 2 weeks later. Control pigs immunized with soya-bean antigen had no IgG anti-OvA 
response. In contrast, in Expt 1 not only did those pigs immunized with soya-bean antigen produce an anti-soya-bean IgG serum response but so did the control pigs immunized with OvA (Fig. 5), the response in these controls being more marked in the older pigs. In Expt 2 , however, when the pigs were fed on a soya-bean-free diet for 2-3 weeks before immunization (Fig. 6), the control pigs immunized with OvA failed to show an anti-soyabean IgG response. This result would suggest that i.p. injection of Quill A alone can stimulate an immune response to dietary antigen, which is further supported by the fact that the smallest response was in group $2 \mathrm{wO}$ when the piglets intake of solids was very limited (Friend et al. 1970).

The $14 \mathrm{wS}$ group in Expt 2 (Fig. 6) failed to show a response to i.p. soya-bean antigen, having similar levels of anti-soya-bean IgG as their OvA-injected controls. This would suggest that they had become hyporesponsive to i.p. soya-bean antigen and that they were orally tolerant. Presumably this had been achieved by the time they were transferred to the soya-bean-free diet at 12 weeks of age. Interestingly this is the age at which they would normally stop sucking from their dams in the family pen system. In marked contrast however, Expt 1 showed that animals of similar age (13wO) with continuous access to soyabean were still responsive to dietary soya-bean (Fig. 5), suggesting that mucosal and systemic tolerance may be compartmentalized. Intraperitoneal immunization alone of soya-bean antigen in the $14 \mathrm{wS}$ group (Fig. 6) failed to produce an anti-soya-bean response, whereas when soya bean was presented either simultaneously (both orally (in the diet) and by i.p. immunization (13wS)) or just orally (13wO) then both groups of pigs responded (Fig. 5). It seems likely, therefore, that Quill A is capable of stimulating the gut immune system as well as a systemic response. Alternatively, Quill A could solely be stimulating a systemic response, but against antigen which had passed across the gut wall (13wO). However, this seems unlikely since comparable pigs (14wS) were shown to be systemically tolerant. Earlier studies have shown that identical regimes of oral immunization may be used to induce systemic tolerance yet stimulate local antibody production (Swarbrick et al. 1979; Challacombe \& Tomasi, 1980), and cellular mechanisms have been identified which may be responsible for the maintenance of this compartmental response (Elson et al. 1979; Green et al. 1982). Gut mucosal tissues have been shown to be a major site of immunoglobulin production (Van Heijden et al. 1987) and this may explain why Quill A challenge and simultaneous feeding of soya bean results in a significant rise of serum antibodies to soya bean.

In several species studied, including humans, prolonged feeding of an antigen results in the induction of a moderate serum IgG response (Peri \& Rothberg, 1981; Husby et al. 1985, 1986; Telemo et al. 1987, 1991; Wold et al. 1987) along with an impaired response to systemic challenge (Filipp \& Boros, 1967; Thomas \& Parrot, 1974; Andre et al. 1975; Swarbrick et al. 1979; Heppell \& Kilshaw, 1982), even when using strong adjuvants. Such a response could provide the organism with a powerful mechanism for avoiding adverse reactions to harmless dietary antigens.

In both Expt 1 and 2 pre-immunization levels of IgG anti-OvA were minimal. In contrast, all pigs had significant IgG anti-soya-bean before immunization with soya-bean antigen. This is likely to be a result of maternal transfer of $\mathrm{IgG}$ anti-soya-bean via the sow's colostrum (Telemo et al. 1991) and the presence of soya bean in the piglets' diet (Miller $e t$ al. 1991).

In Expt 1 there was no significant rise in IgG anti-soya-bean, when expressed as specific activity, between 2 and 11 weeks of age in pre-injected pigs, even though they were being given soya bean. This contrasts with previous observations made on early weaned pigs (Bailey et al. 1993) which showed a marked IgG response to dietary soya bean before the development of oral tolerance by 7 weeks. It should be noted that in this experiment the 
piglets were abruptly weaned onto a soya-bean-based diet at 3 weeks of age. Interestingly, this period of sensitivity to soya-bean in early weaned pigs is associated with susceptibility to enteritis and E. coli diarrhoea. It may be possible, therefore, that the reported absence of digestive upset or diarrhoea in pigs reared under the Family Pen system (C. T. Whittemore, unpublished results) reflects the lack of a damaging hypersensitivity to soya bean in the weaning diet before the onset of oral tolerance.

The authors wish to thank Mr Dilip Patel and Mr Bob Prince for technical assistance, $\mathrm{Mr}$ Peter Finney for taking care of and handling the pigs and Dr Colin Morgan for formulating the feeds. Also special thanks to Professor John Webster for his helpful comments on the manuscript. This work was supported by an AFRC link grant.

\section{REFERENCES}

Andre, C., Heremans, J. F., Vaerman, J. P. \& Cambiaso, C. (1975). A mechanism for the induction of immunological tolerance by antigen feeding: antigen-antibody complexes. Journal of Experimental Medicine 142, $1509-1519$.

Bailey, M., Miller, B. G., Telemo, E., Stokes, C. R. \& Bourne, F. J. (1993). Specific immunological unresponsiveness following active primary responses to proteins in the weaning diets of pigs. International Archives of Allergy and Applied Immunology 101, 266-271.

Challacombe, S. J. \& Tomasi, T. (1980). Systemic tolerance of secretory immunity after oral immunisation. Journal of Experimental Medicine 152, 1459-1472.

Elson, C. O., Heck, J. A. \& Strober, W. (1979). T-cell regulation of murine IgA synthesis. Journal of Experimental Medicine 149, 632-643.

Fahey, J. L. \& McKelvey, E. (1965). Quantitative determination of serum immunoglobulins in antibody agar plates. Journal of Immunology 94, 84-90.

Filipp, G. \& Boros, B. (1967). The induction of immunological tolerance by antigen feeding. The effect of thymectomy on orally induced tolerance. Journal of Allergy 39, 167-170.

Friend, D. W., Gorrill, A. \& MacIntyre, T. (1970). Performance and proteolytic enzyme activity of the suckling piglet creep-fed at one or three weeks of age. Canadian Journal of Animal Science 50, 349-354.

Green, D. R., Gold, J., St Martins, S., Gershon, R. \& Gershon, R. K. (1982). Microenvironmental immunoregulation: possible role of contrasuppressor cells in maintaining immune response in gut-associated lymphoid tissues. Proceedings of the National Academy of Sciences (USA) 79, 889. 892.

Heppell, L. M. \& Kilshaw, P. (1982). Immune responses in guinea pigs to dietary protein. I. Induction of tolerance by feeding ovalbumin. International Archives of Allergy and Applied Immunology 68, 54-59.

Holmgren, J., Svennerholm, A. M. \& Ahrén, C. H. (1981). Nonimmunoglobulin fraction of human milk inhibits bacterial adhesion (haemagglutination) and enterotoxin binding of Escherichia coli and Vibrio cholerae. Infection and Immunity 33, 136-141.

Husby, S., Jensenius, J. C. \& Svehag, S. E. (1985). Passage of undegraded dietary antigen into the blood of healthy adults. Quantification, estimation of size distribution and relation of uptake to levels of specific antibodies. Scandinavian Journal of Immunology 22, 83-92.

Husby, S., Jensenius, J. C. \& Svehag, S.-E. (1986). Passage of undegraded dietary antigen into the blood of healthy adults. Further characterization of the kinetics of uptake and size distribution of the antigen. Scandinavian Journal of Immunology 24, 447-455.

Miller, B. G., Bailey, M., Telemo, E. \& Stokes, C. R. (1991). Hypersensitivity to soya bean protein in early weaned pigs. In Proceedings of the 2nd Conference on Toxic Factors in Crop Plants [J. P. F. D'Mello and C. M. Duffus, editors]. Edinburgh.

Miller, B. G., Newby, T. J., Stokes, C. R., Hampson, D. J., Brown, P. J. \& Bourne, F. (1984). The importance of dietary antigen in the cause of postweaning diarrhea in pigs. American Journal of Veterinary Research $\mathbf{4 5}$, $1730-1733$.

Newby, T. J., Stokes, C. R. \& Bourne, F. (1982). Immunological activities of milk. Veterinary Immunology and Immunopathology 3, 67-94.

Peri, B. A. \& Rothberg, R. M. (1981). Specific suppression of antibody production in young rabbit kits after maternal ingestion of bovine serum albumin. Journal of Immunology 127, 2520-2525.

Stokes, C. R. \& Swarbrick, E. (1977). Induction of tolerance after oral feeding of soluble protein antigen. Biochemical Society Transactions 5, 1573-1574.

Stolba, A. \& Wood-Gush, D. G. M. (1984). The identification of behavioural key features and their incorporation into a housing design for pigs. Annales de Recherches Vétérinaires 15, 287-289.

Swarbrick, E. T., Stokes, C. R. \& Soothill, J. (1979). Absorption of antigens after oral immunisation and the simultaneous induction of specific systemic tolerance. Gut 20, 121-125. 
Telemo, E., Bailey, M., Miller, B. G., Stokes, C. R. \& Bourne, F. J. (1991). Dietary antigen handling by mother and offspring. Scandinavian Journal of Immunology 34, 689-696.

Telemo, E., Jacobsson, I., Weström, B. \& Folkesson, H. (1987). Maternal dietary antigens and the immune response of the offspring in the guinea pig. Immunology 62, 35-38.

Thomas, H. C. \& Parrot, D. (1974). The induction of tolerance to a soluble protein antigen by oral administration. Immunology 27, 631-639.

Van Heijden, P. J., Stok, W. \& Bianchi, A. T. J. (1987). Contributions of immunoglobulin secretory cells in the murine small intestine to total 'background' immunoglobulin production. Immunology 62, 551-555.

Wold, A. E., Dahlgren, U. I., Ahlstedt, S. \& Hanson, L. А. (1987). Lack of IgA antibody response in secretions of rat dams during long-term ovalbumin feeding. Induction of systemic tolerance in pups but not in adult rats. International Archives of Allergy and Applied Immunology 84, 332-338.

Wold, A. E., Dahlgren, U. I. H., Ahistedt, S. \& Hanson, L. A. (1988). Rats are sensitive to induction of tolerance by feeding only at young age. Monographs of Allergy 24, 251-252. 